\title{
Pernicious Anemia Associated Autoimmune Diseases in a Sub Saharian African Internal Medicine Service
}

\author{
Abdoulaye Pouye*, Seynabou Fall Dieng, Daher Abdoukarim Oumar, \\ Fatou Samba Diago N’Diaye, Nafissatou Diagne Sakho, Atoumane Faye, \\ Souhaibou N'Dongo \\ Medical Clinic 1 University Teaching Hospital Aristide le Dantec/Cheikh Anta Diop University of Dakar, \\ Dakar, Senegal \\ Email: ${ }^{\text {docpouye@yahoo.fr }}$
}

Received 27 June 2014; revised 24 July 2014; accepted 20 August 2014

Copyright (C) 2014 by authors and Scientific Research Publishing Inc.

This work is licensed under the Creative Commons Attribution International License (CC BY). http://creativecommons.org/licenses/by/4.0/

(c) (i) Open Access

\section{Abstract}

Introduction: Pernicious anemia is an autoimmune disease. It is characterized by the presence of an autoimmune atrophic gastritis and various autoantibodies that lead to a vitamin B12 deficiency responsible for a macrocytic anemia. It is frequently associated with other specific or non-organspecific autoimmune diseases. We report six patients with pernicious anemia associated with other autoimmune diseases. Patients and Results: There were six patients ( 4 females/2 males), mean age of 39.67 years. In all cases it was found macrocytic anemia. The average $\mathrm{Hb}$ was 6.08 $\mathrm{g} / \mathrm{dl}$ and the average MGV: $110.67 \mathrm{fl}$. Bone marrow aspiration was performed in all patients. Megaloblastosis compatible with a lack of vitamin B12 or folic acid was constant. Determination of serum vitamin B12 was low in all cases while folic acid levels were within standards. Immunologically it was found in all patients, a positivity of anti-intrinsic factor antibody and/or antiparietal cells antibody at rates up to 67 times over normal ranges. Pernicious anemia was associated with autoimmune thyroid dysfunction in 4 patients. It was two cases of Hashimoto thyroiditis at hypothyroidic phase (high TSHus, thyréoperoxydase anti-antibody positive (over $10 \mathrm{~N}$ ) in both cases and Graves' disease in the two other cases. Pernicious anemia was associated with a syndrome of primary antiphospholipid antibody in a case. Furthermore pernicious anemia was found in a patient autoimmune type 1 diabetes with strongly positive anti -GAD antibodies and rheumatoid arthritis by retaining it in the diagnosis of multiple autoimmune syndrome. Conclusion: These cases illustrate the existence of the association of pernicious anemia with other autoimmune diseases in our context. This should encourage practitioners to seek hided autoimmune diseases when they consider the diagnosis of pernicious anemia.

\footnotetext{
${ }^{*}$ Corresponding author.
} 


\section{Keywords}

\section{Pernicious Anemia, Auto-Immune Diseases, Auto Immune Thyroid Dysfunction, Multiple Auto-Immune Syndrome}

\section{Introduction}

Pernicious anemia also known as Biermer disease is a complex disorder consisting of hematological, gastric and immunological alterations. Diagnosis of this disease relies on histologically proven atrophic body gastritis. The immunological mechanism of this disease is demonstrated by the presence of auto-antibodies anti-parietal cells and anti intrinsic factor. For a while it had been considered rare in Sub-Saharian African countries, but an increasing number of publications highlight the interest towards this disease whose prevalence is unknown in this area [1]-[4]. Its association with other auto-immune diseases is well known but poorly described in Black African people [1]-[4]. We studied diagnostic, therapeutic and evolutive aspects of Biermer disease associated with other auto-immune diseases through six new cases in the Internal medicine ward of University Teaching Hospital of Dakar.

\section{Cases}

We report six cases among a cohort of 80 persons followed for pernicious anemia in the internal medicine service of university teaching hospital Aristide le Dantec. Biermer disease diagnosis criteria were macrocytic anemia associated with megaloblastocytosis, low blood level of B12 vitamin, positivity of at least one of the following antibody: anti intrinsic factor or anti parietal cell; and or proven atrophic gastritis. The diagnosis was made when the patient met four or more criteria. We selected six patients who had in addition an organ or systemic dysfunction with specific immunological markers according to the defined diagnosis criteria of Hashimoto, Grave Basedow, systemic lupus erythematous, rheumatoid arthritis, auto immune diabetes and anti-phospholipid syndrome.

There were six patients ( 4 females/2 males), mean age of 39.67 years. Macrocytic anemia was constant. The average $\mathrm{Hb}$ was $6.08 \mathrm{~g} / \mathrm{dl}$ and the average MGV: $110.67 \mathrm{fl}$.

Bone marrow aspiration was performed in all patients revealing a constant megaloblastosis. Determination of serum vitamin B12 was low in all cases while folic acid levels were within standards. Immunologically it was found in all patients, a positivity of anti-intrinsic factor antibody and/or anti- parietal cells antibody.

Pernicious anemia was associated in 4 patients with autoimmune thyroid dysfunction consisting in two cases of Hashimoto thyroiditis at hypothyroidic phase (high TSHus, thyréoperoxydase anti-antibody positive (over 10 $\mathrm{N}$ ) in both cases and Graves' disease in the two other cases.

Pernicious anemia was associated with a syndrome of primary antiphospholipid antibody in one case. Furthermore pernicious anemia was found in a patient with multiple autoimmune syndrome associating autoimmune type 1 diabetes with strongly positive anti -GAD antibodies and rheumatoid arthritis.

Patients epidemiological, clinical, paraclinical, treatment, evolution at day eight characteristics are summarized in the Table 1.

\section{Discussion}

Our study report six new cases of pernicious anemia associated with other auto-immune diseases. It is the most important series of patients published in the Sub-Saharian african countries. In Senegal, respectively three and one case had been previously reported [1] [2]. In Cote d'Ivoire Lokrou [4] reported one association of pernicious anemia and type I diabete. Our cases were predominantly female like in the other studies [2] [5] [6] that seem to be related to the global female predominance of auto-immune diseases. Pernicious anemia can preceed, succeed or occur simultaneously with the associated auto-immune disease. These diseases were dominated by thyroid dysfunction Hashimoto thyroiditis as previously reported [5]-[7] or Grave Basedow disease. In a population of pernicious anemia patients associated with other auto-immune diseases, Zulfiqar [5]-[7] noticed a thyroid dysfunction in $77 \%$ of cases and $61 \%$ of them were Hashimoto thyroiditis. Such findings have not been reported yet in sub saharian countries. 


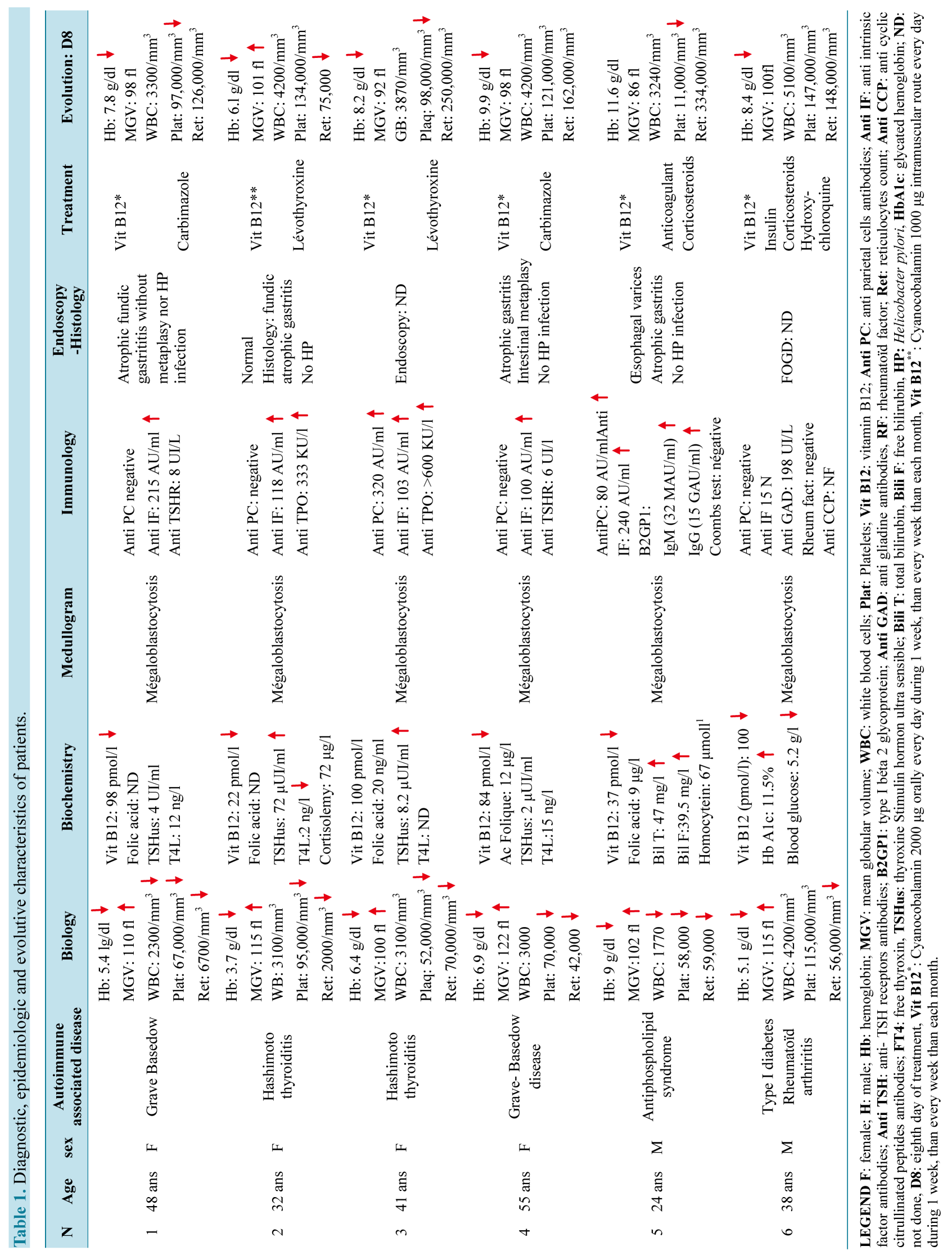


The association of pernicious anemia and diabetes was reported in our geographical area [5]-[7] and is well known. But the association with anti-phospholipid syndrome is less frequent. It was reported by Zulfiqar but not found in Sub-Saharian Africa. The diagnosis of this first known case in Africa was made while researching thrombophily suggested by atypical location of thrombo-embolic manifestations. This case was particular because of the co-existence of a hyperhomocysteinemia which is another thrombophylic risk factor The lack of recurrence after acute thrombo embolic phase with only vitamin B12 therapy suggest a participation of hyperhomocysteinemia in the occurrence of thrombo-embolic manifestations in this case.

In one case there was a multiple auto-immune syndrome associating pernicious anemia, rheumatoid arthritis and auto-immune type I diabetes. These complex cases were classified by Humbert in three types [8] but some cases don't match this classification and remain unclassified.

Symptoms revealing pernicious anemias associated with other auto-immune diseases are numerous and non specific. Anemia was quasi constant in our cases like in those reported in Black African patients [1]-[4], acquired diffuse melanodermia which is a particularity of pernicious anemia in Black population and found in $80 \%$ of cases reported by Diop [1], was noticed in only one case in our series. Same for sensitive neuropathy and glossitis. These symptoms were found respectively in near half of the cases reported by Diop and in $23 \%$ of those reported by Ndiaye [2] We haven't noticed diarrhea, constipation or gastric pain in our series but the size of our population study did not allow us any interpretation. Biological characteristics of our population are similar to those previously published in Subsaharian Africa. Macrocytic anemia was almost constant coexisting with other cytopenia realizing a bicytopenia. or pancytopenia [2] [4]. Medullar megaloblastocytosis was frequently associated with haemolysis. In this context of dysimmunity an auto-immune hemolytic anemia must be evoqued, but in all our cases Coombs test was negative. Low blood level of vitamin B12 was noticed in all our cases like in other publications [1] [6].

Positivity of auto-immune markers like anti intrinsic factor and anti parietal cells antibodies with a respective specificity of $95 \%$ and $50 \%$ [6] is a major diagnostic criteria for diagnosing Biermer disease. Anti intrinsic factor were more frequently found (6 cases). Body gastric atrophy is another diagnosis criteria reported in $86 \%$ of cases by N'diaye F.S. It was constantly found in subjects who did have and digestive endoscopic examination in our serie. Histologically atrophic gastritis can be associated with an intestinal type metaplasy that can lead to gastric cancer. Gastric endoscopy must be regularly performed to detect as earlier as possible the malignant transformation in case of isolated pernicious anemia and when there is another autoimmune disease associated [9].

Treatment of pernicious anemia alone or associated with another auto-immune disease is based upon lifetime parenteral administration of vitamin B12. But high doses of vitamin B12 given orally are effective and very useful in patients with thrombopenia and when health care facilities are poor [6]. Treatment of the associated disease were corticosteroids or immunomodulators such hydroxychloroquine associated with specific measures like insulin, levothyroxine or carbimazole.

\section{Conclusion}

Pernicious anemia associated with other auto-immune diseases is not frequent in a Black African population. Physicians should pay attention to this association because of the lack of specificity of clinical symptoms. Macrocytic anemia is constant and haemogram is a convenient diagnostic tool in case of suspicion of a pernicious anemia or an auto-immune disease.

\section{References}

[1] Diop Madoky, M., Berthe, A.,Touré, P.S., Mahamat, Y., Leye, M.Y., Diousse, P., Leye, A. and Ka, M.M. (2013) Peculiarities of Biermer Disease in a Senegalese Internal Medicine Department: A 6 Year Prospective Study. Journal of Blood Disorders Transfusion, 5, 1179.

[2] Ndiaye, F.S., Fall, S., Sarr, A., Laraki, S.D., Ka, M.M. and Diop, M.T. (2009) Données Actuelles sur la Maladie de Biermer Étude Rétrospective de 26 Observations Sénégalaises. Hematology, 15, 473-477.

[3] Segbena, A.Y., Ambofo-Planche, Y., Gbadoe, A.D., et al. (2003) A Propos de Quatre Observations de Maladie de Biermer en Afrique de l’Ouest. Médecine Tropicale, 63, 593-596.

[4] Lokrou, A., Doumbia, A. and Tolo, A. (2009) Diabete de Type 1 et Maladie de Biermer chez une Patiente Noire Africaine en Cote-d’Ivoire. Médecine des Maladies Métaboliques, 3, 277-279. 
[5] Zulfiqar, A.A., Pennaforteb, J.L., Drame, M., Mahmoudia, R., Andres, E. and Novellaa, J.L. (2014) When Pernicious Anemia Is Invited in Multiple Autoimmune Syndromes in the Elderly. European Geriatric Medicine, 5, 133. http://dx.doi.org/10.1016/j.eurger.2013.12.012

[6] Loukili, N.H., Noel, E., Blaison, G., Goichot, B., Kaltenbach, G., Rondeau, M. and Andrés, E. (2004) Données Actuelles sur la Maladie de Biermer. La Revue de Médecine Interne, 25, 556-561. http://dx.doi.org/10.1016/j.revmed.2004.03.008

[7] Zulfiqar, A.A., Drame, M., Pennaforte, J.-L. and Andres, E. (2012) Fréquence des Maladies Auto-Immunes Chez 188 Patients Atteints de la Maladie de Biermer. La Revue de Médecine Interne, 33S, A90-A198.

[8] Humbert, P. and Dupond, J.L. (1988) Multiple Autoimmune Syndromes. Annales de Médecine Interne, 139, $159-168$.

[9] Petersson, F., Borch, K. and Franze’n, L.E. (2002) Prevalence of Subtypes of Intestinal Metaplasia in the General Population and in Patients with Autoimmune Chronic Atrophic Gastritis. Scandinavian Journal of Gastroenterology, 37, 262-266. http://dx.doi.org/10.1080/003655202317284156 
Scientific Research Publishing (SCIRP) is one of the largest Open Access journal publishers. It is currently publishing more than 200 open access, online, peer-reviewed journals covering a wide range of academic disciplines. SCIRP serves the worldwide academic communities and contributes to the progress and application of science with its publication.

Other selected journals from SCIRP are listed as below. Submit your manuscript to us via either submit@scirp.org or Online Submission Portal.
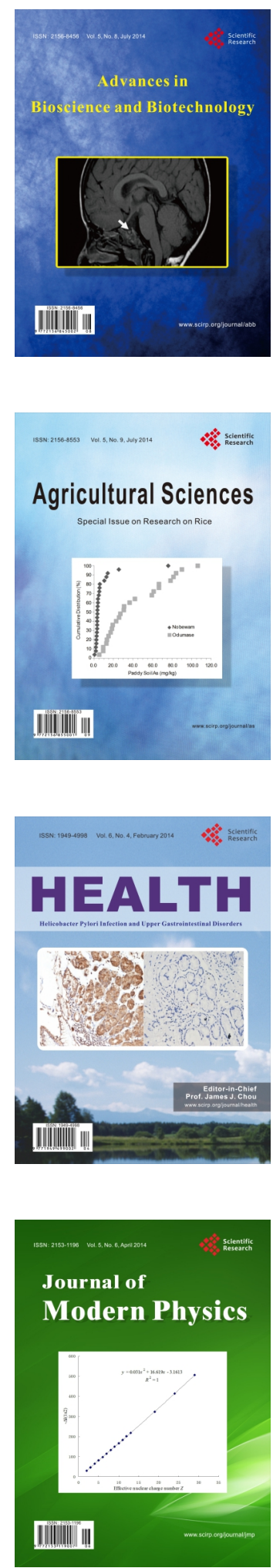
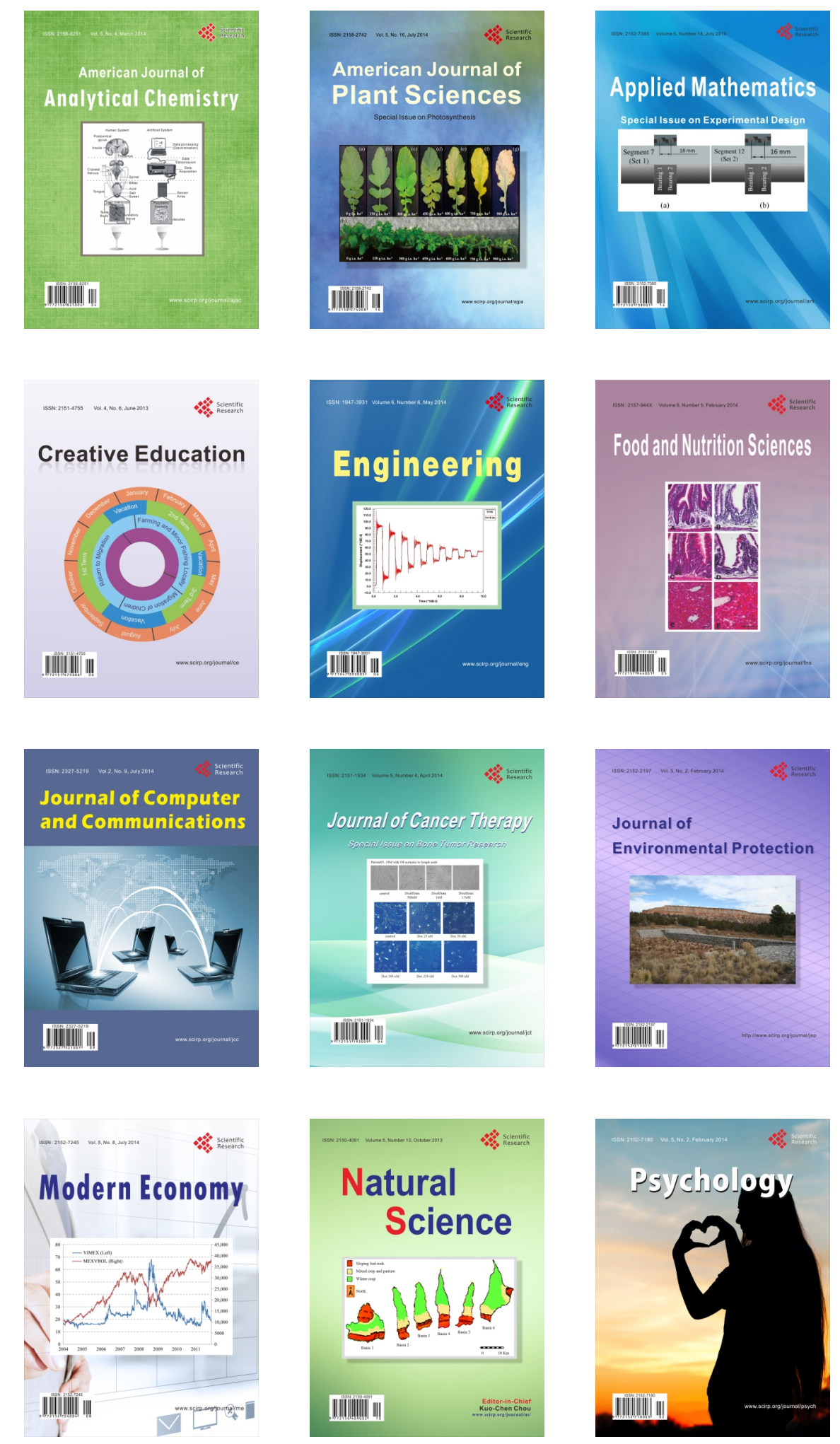